\title{
Outcomes of kidney transplant recipients admitted to the intensive care unit: a retrospective study of 200 patients
}

\author{
Damien Guinault', Arnaud Del Bello', Laurence Lavayssiere', Marie-Béatrice Nogier', Olivier Cointault',
} Nicolas Congy ${ }^{2}$, Laure Esposito ${ }^{1}$, Anne-Laure Hebral ${ }^{1}$, Olivier Roques ${ }^{1}$, Nassim Kamar ${ }^{1,3,4}$ and Stanislas Faguer ${ }^{1,3,5^{*}}$ (D)

\begin{abstract}
Background: Risk of over-immunosuppression or immunization may mitigate the overall and long-term renal outcomes of kidney transplant recipients (KTR) admitted to the ICU in the modern era but remain poorly described. Thus, there is an unmet need to better characterize the survival of KTR admitted to the ICU, but also the renal and immunological outcomes of survivors.

Methods: Retrospective observational study that included 200 KTR admitted between 2010 and 2016 to the ICU of a teaching hospital (median age 61 years [IQR 50.7-68]; time from transplantation 41 months [IQR 5-119]). Survival curves were compared using the Log-rank test.

Results: Mortality rates following admission to the ICU was low (26.5\% at month-6), mainly related to early mortality (20\% in-hospital), and predicted by the severity of the acute condition (SAPS2 score) but also by Epstein Barr Virus proliferation in the weeks preceding the admission to the ICU. Acute kidney injury (AKI) was highly prevalent (85.1\%). Progression toward chronic kidney disease (CKD) was observed in $45.1 \%$ of survivors. $15.1 \%$ of survivors developed new anti-HLA antibodies (donor-specific antibodies $9.2 \%$ of cases) that may impact the longterm renal transplantation function.

Conclusions: Notwithstanding the potential biases related to the retrospective and monocentric nature of this study, our findings obtained in a large cohort of KTR suggest that survival of KTR admitted in ICU is good but inICU management of these patients may alter both survival and AKI to CKD transition, as well as HLA immunization. Further interventional studies, including systematic characterization of the Epstein Barr virus proliferation at the admission (i.e., a potential surrogate marker of an underlying immune paralysis and frailty) will need to address the optimal management of immunosuppressive regimen in ICU to improve survival but also renal and immunological outcomes.
\end{abstract}

Keywords: Renal transplantation, HLA immunization, Intensive care unit, Outcomes

\section{Background}

About 10\% of kidney transplant recipients (KTR) experience a life-threatening disease requiring admission in an intensive care unit (ICU) [1-7]. Most admissions occur more than 6 months after the renal transplantation $[3-5,8,9]$. The main causes of admission were acute respiratory failure

\footnotetext{
* Correspondence: stanislas.faguer@inserm.fr

'Département de Néphrologie et Transplantation d'organes, Unité de

Réanimation, Hôpital Rangueil, Centre Hospitalier Universitaire de Toulouse,

1, avenue Jean Poulhes, 31059 Toulouse, France

${ }^{3}$ Université Paul Sabatier, Toulouse III, F-31000 Toulouse, France

Full list of author information is available at the end of the article
}

(ARF) and septic shock, followed by cardiovascular complications, acute kidney injury (AKI), drug-related complications and neoplasia $[4,10]$.

In-hospital mortality after admission to the ICU is mostly related to the cause of admission and the number of organ failures at presentation, whereas the characteristics of the renal transplantation are not associated with the outcomes $[3,4,6]$. Whether these findings hold true in the modern era characterized by an increase of transplantations at high risk of surgical and immunological

(c) The Author(s). 2019 Open Access This article is distributed under the terms of the Creative Commons Attribution 4.0 International License (http://creativecommons.org/licenses/by/4.0/), which permits unrestricted use, distribution, and 
complications and with widespread use of prophylaxis for opportunistic infections remain to be addressed.

KTR are at higher risk of severe AKI in the ICU, compared to unselected critically ill patients $[3,11]$, and up to $40 \%$ of KTR will required renal replacement therapy (RRT). AKI is now recognized as a cause of chronic kidney disease (CKD), and estimated glomerular filtration rate (eGFR) before the injury is a strong predictive factor of progression toward CKD [12]. In old studies, the renal outcome was poor, ranging from 20 to $30 \%$ of patients with eGFR decline after ICU stay. KTR that develop AKI have a relative risk of graft loss of 3.2 , and up to $20 \%$ of patients will ultimately lose their renal graft [13].

Similarly to unselected critically ill patients, renal outcome of KTR results from the combination of the underlying CKD (i.e, basal eGFR), the use of nephrotoxicants in the ICU, and episodes of ischemic, hemodynamic or septic AKI $[3,4,14]$. In the setting of renal transplantation, immunological injuries may also promote the progression of graft dysfunction observed after ICU admission. Indeed, the withdrawal of immunosuppressive drugs and/or red blood cells (RBC) transfusion may lead to the development of de novo donor-specific antibodies during or after the stay in the ICU $[15,16]$. This may reduce the graft survival in ICU survivors and reduce the access to a subsequent transplantation in patients who lost their graft function. To date, no study accurately assessed the immunological outcome in KTR admitted in ICU.

In this study, which included a large cohort of 200 KTR admitted in ICU over a 6 years period, we aimed to identify the predictive factors for in-hospital mortality, to characterize the predictive factors of progression from AKI of CKD, and to assess the risk of anti-HLA immunization, two factors associated with long-term survival.

\section{Patients and methods}

In this retrospective single-center study, we included all KTR admitted between January 2010 and June 2016 to the ICU of the Department of Nephrology and Organ Transplantation at the University Hospital of Toulouse (France), a 10-bed tertiary care ICU backed by a 30 beds-unit of solid organ transplantation, and with 24-ha-day intensivist.

To be included in this study, patients met the following criteria: (i) over 18 years of age, (ii) to have received a renal transplantation before the admission, and (iii) an admission to the ICU for acute conditions. Patients admitted for a close monitoring just after the renal transplantation, and those with known irreversible graft failure, were excluded from the analysis. Only the first admission was reported.

According to the French law related to retrospective observational studies and our Institutional Review Board
(University Hospital of Toulouse - Office of Research, Development and Innovation), the need for written consent was waived.

The primary objective of the study was to identify the predictive factors of death in the hospital of KTR admitted to the ICU. Secondary objectives were the characterization of the risk to develop AKI to CKD transition and to acquire HLA immunization.

\section{Clinical characteristics}

Clinical and biological data were collected from the computerized charts of the patients. The following parameters related to transplantation were collected: age at transplantation, cause of renal disease, immunosuppressive regimen, episodes of biopsy-proven antibody or Tcell-mediated rejection (ABMR and TCMR), EBV or CMV replication in blood or BK virus shedding in urine within the 6 months preceding the admission to the ICU. The parameters related to the ICU stay included age at admission, gravity scores, causes for admission, infections, organ failures, RBC transfusions, and immunosuppression management. Changes in immunosuppression were not standardized in our ICU and were left at the discretion of each physician. CKD was assessed at month 1 and 6 in survivors according to the CKD KDIGO staging [17].

\section{Immunological tests}

Assessment of anti-HLA immunization was performed according to our institutional protocol (i.e. every 12 months or after events at risk of anti-HLA immunization like RBC transfusion, acute rejection), with the Luminex ${ }^{\circ}$ technique. A baseline value of $>500$ was considered positive.

\section{Statistical analyses}

Continuous variables are reported as their median and interquartile ranges (IQR), and discontinuous variables as numbers and percentages. Univariate analyses of in-hospital mortality were performed using the Mann-Whitney or Fischer' exact tests, as appropriate. Multivariate analyses were performed using a step-by-step logistic regression model. All variables associated with in-hospital survival by univariate analysis $(p<0.1)$ were included in the multivariate analysis. Survival curves were drawn according to the Kaplan-Meier method and compared with the LogRank test (univariate analysis). Statistical significance was assumed at $p<0.05$. Statistical analyses were performed using the GraphPad Prism6 (San Diego, CA, USA) and Xlstat softwares (Addinsoft, Paris, France). 


\section{Results}

From January 2010 to June 2016, 286 KTR were admitted at least once to our ICU, including 200 that met the inclusion criteria (median age 61 years [IQR 50.7-68]; male to female ratio 126/74; time from transplantation 41 months [IQR 5-119]; Fig. 1). During this period 1240 patients received renal transplantation in our transplantation unit, and 95 out of these 1240 (7.7\%) were admitted to the ICU. Main characteristics of the transplantation and at the admission are summarized in Tables 1 and 2 .

\section{Transplantation characteristics}

Immunosuppressive regimen included induction therapy in 162 patients. At admission, patients received a combination of calcineurin inhibitors (81.3\%; tacrolimus $74 \%$ ), antimetabolites (82.3\%; mycophenolic acid 79.3\%), mTOR inhibitors (19.2\%) and/or steroids (92.9\%). Overall, 123 patients received an immunosuppressive regimen including steroids, mycophenolic acid and calcineurins inhibitors.

Twenty-six (13\%) and 34 (17\%) out of the 200 patients had presented with an ABMR and TCMR before the admission in the ICU (12 (6\%) developed both ABMR and
TCMR). When available within the 6 months preceding the admission to the ICU, CMV and EBV replication in the blood were observed in $16 / 142$ patients (11.3\%), 39/ 127 (30.7\%), respectively.

\section{Characteristics in the ICU}

At admission, median SOFA gravity score was 6 [IQR 4-8]. Main causes of admission were ARF (27.5\%), septic shock (26.5\%), post-operative period (peritonitis, hemorrhage, $23 \%$ ), acute neurological disorder (6\%), AKI requiring RRT $(5 \%)$ or cardiac arrest (1\%).

Altogether, 114/200 admissions (57\%) were related to an infection (lungs $(28.5 \%)$, urine $(13 \%)$, gut $(12 \%)$ or other $(3.5 \%)$ ). Pyogenes-related infections were diagnosed in 101 patients, whereas aspergillosis, candidemia, pneumocystosis and CMV infections were identified in $8,8,7$ and 5 patients, respectively. Multiple infections were identified in 29 patients (14.5\%).

Median time of hospitalization in the ICU was 5 days [IQR 2-10]. Among the 200 individuals, 107 (53.5\%) required mechanical ventilation, and 97 (48.5\%) required vasopressive drugs. One hundred and seventy-one patients (85.5\%) developed AKI, including 113 (56.5\%) with

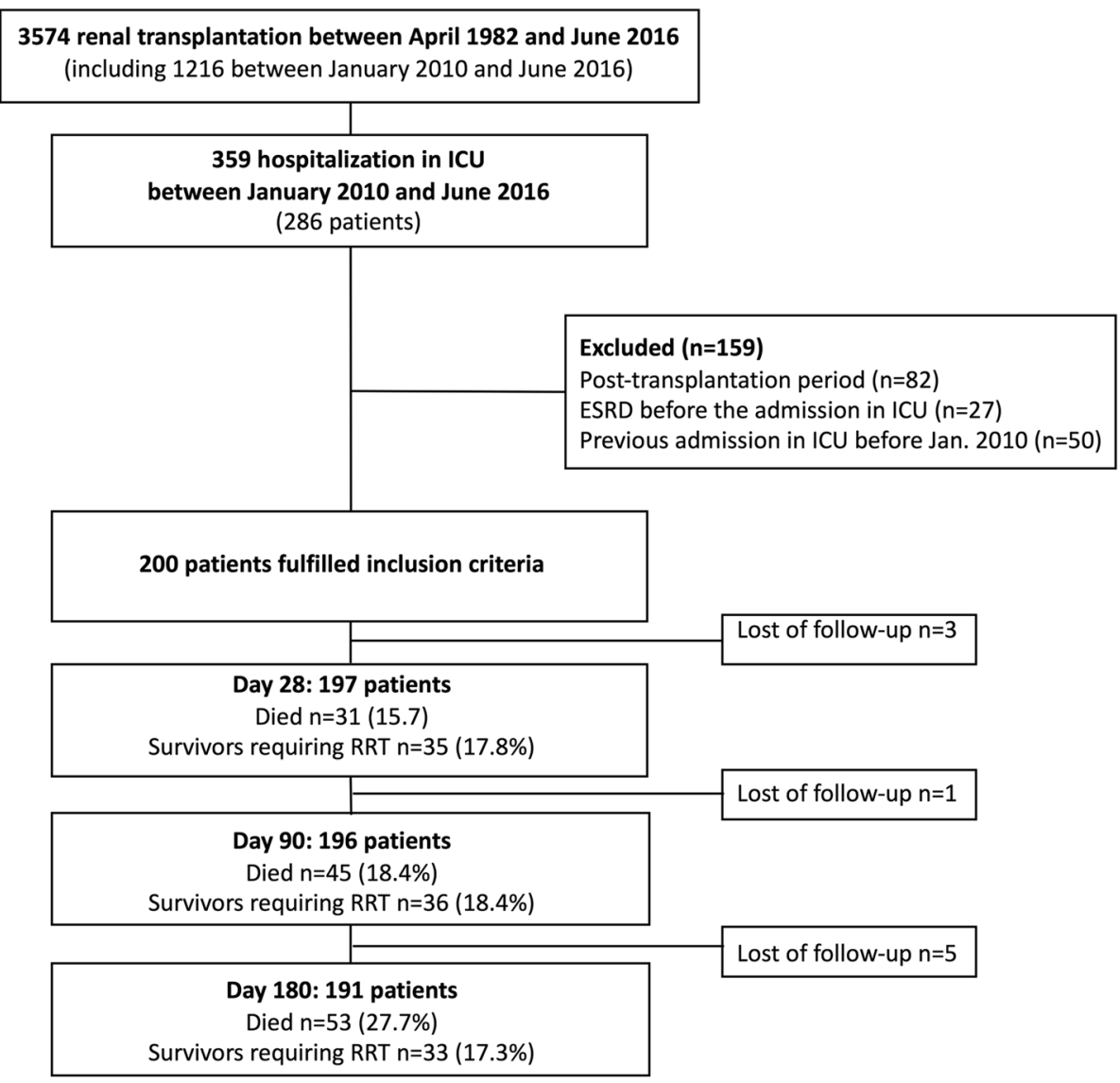

Fig. 1 Flowchart of the study 
Table 1 Characteristics of the 200 kidney transplant recipients before admission in ICU

\begin{tabular}{|c|c|c|c|c|}
\hline Characteristics & $\begin{array}{l}\text { Total } \\
N=200\end{array}$ & $\begin{array}{l}\text { Survivors } \\
N=160\end{array}$ & $\begin{array}{l}\text { In-hospital death } \\
N=40\end{array}$ & $p$ \\
\hline Age $(n, \%)$ & $61[51-68]$ & $60[49-66]$ & $65[58-70]$ & 0.07 \\
\hline Male gender (n, \%) & $126(63)$ & $97(60.6)$ & $29(72.5)$ & 0.20 \\
\hline \multicolumn{5}{|l|}{ Comorbidities (n, \%) } \\
\hline Diabetes mellitus & $71(35.5)$ & $56(35)$ & $15(37.5)$ & 0.81 \\
\hline Heart disease (left ventricular systolic function < 45\%) & $97(48.5)$ & $73(45.5)$ & $24(60)$ & 0.11 \\
\hline Peripheral arterial disease & $23(11.5)$ & $60(37.5)$ & $24(60)$ & 0.01 \\
\hline Solid cancer & $11(5.5)$ & $6(3.8)$ & $5(12.5)$ & 0.05 \\
\hline Active hematological malignancy & $9(4.5)$ & $6(3.8)$ & $3(7.5)$ & 1.00 \\
\hline \multicolumn{5}{|l|}{ Transplantation characteristics (n, \%) } \\
\hline Deceased donor & $15(7.5)$ & $14(8.7)$ & $1(2.5)$ & 0.31 \\
\hline First kidney transplantation & $166(83)$ & $136(85)$ & $30(75)$ & 0.20 \\
\hline \multicolumn{5}{|l|}{ Induction } \\
\hline No & $30(15)$ & $23(14.4)$ & $7(17.5)$ & 0.62 \\
\hline Polyclonal antibodies & $90(45)$ & $74(46.3)$ & $16(40)$ & 0.58 \\
\hline IL2R blocking agents & $72(36)$ & $57(35.6)$ & $15(37.5)$ & 0.85 \\
\hline \multicolumn{5}{|l|}{ Immunosuppressive regimen } \\
\hline Steroids & $184(92)$ & $148(92.5)$ & $36(90)$ & 1.00 \\
\hline $\mathrm{CNI}$ & $161(80.5)$ & $131(81.8)$ & $30(75)$ & 0.49 \\
\hline Tacrolimus & $123(61.5)$ & $104(65)$ & $19(4.8)$ & 0.97 \\
\hline Antimetabolites & $163(81.5)$ & $137(85.6)$ & $26(65)$ & 0.008 \\
\hline \multicolumn{5}{|l|}{ MMF } \\
\hline mTOR inhibitors & $36(18)$ & $29(18.1)$ & $7(17.5)$ & 1.00 \\
\hline Belatacept & $8(4)$ & $6(3.8)$ & $2(5)$ & 0.65 \\
\hline CNI, MPA, Steroids association & $x x$ & $x x$ & $x x$ & \\
\hline \multicolumn{5}{|l|}{ History of acute rejection } \\
\hline Antibody mediated rejection & $26(13)$ & 19 (11.8) & $7(17.5)$ & 0.43 \\
\hline T-cell mediated rejection & $34(17)$ & $28(17.5)$ & $6(15)$ & 0.82 \\
\hline \multicolumn{5}{|l|}{ Viral status before the admission ${ }^{\#}(\mathrm{n}, \%)$} \\
\hline Blood Cytomegalovirus detection ( $n=142$ ) & $16(11.3)$ & 9/107 (8.4) & $7 / 35(20)$ & 0.07 \\
\hline Blood Epstein-Barr virus detection $(n=127)$ & $39(30.7)$ & $24 / 96(25)$ & $15 / 31(48)$ & 0.02 \\
\hline Urine BK virus shedding $(n=115)$ & $28(24.3)$ & $18 / 90(20)$ & $10 / 25(40)$ & 0.04 \\
\hline \multicolumn{5}{|l|}{ Immunological status before the admission in ICU (n, \%) } \\
\hline Anti-HLA immunization $(n=188)$ & $71(38)$ & $59 / 152(38)$ & $12 / 36(33)$ & 0.57 \\
\hline Donor-specific antibodies & $23(12.2)$ & $19(12.5)$ & $4(11.1)$ & 1.00 \\
\hline
\end{tabular}

KDIGO stage 3 AKI and 103 (51.5\%) that required RRT. One hundred and forty-two out of the 200 patients (71\%) benefitted from RBC transfusion.

\section{Management of immunosuppression in the ICU}

At the admission, median residual concentration of tacrolimus and ciclosporine-A were $6.6 \mathrm{ng} / \mathrm{mL}$ [IQR 4.6-11.2] and $127 \mathrm{ng} / \mathrm{mL}$ [IQR 77-223], respectively. Prednisolone was switched to hydrocortisone ( 150 to $300 \mathrm{mg} /$ day) in 42 patients, including 35 with septic shock. Calcineurin inhibitors were withdrawal in 40 patients (20\%) and concentration targets were reduced in the others (tacrolimus residual 5-8 ng/mL; cyclosporine-A residual (70-220 ng/ $\mathrm{mL})$. Antimetabolites were stopped in $61 / 163$ patients (37.4\%), including 19 with sepsis. In 48 out of these 61 patients, the dose of steroids was increased. Overall, the immunosuppressive regimen was modified in 155 patients $(77.5 \%)$. 
Table 2 Characteristics of the 200 kidney-transplant recipients at the admission in ICU and during ICU stay

\begin{tabular}{|c|c|c|c|c|}
\hline Characteristics & $\begin{array}{l}\text { Total } \\
N=200\end{array}$ & $\begin{array}{l}\text { Survivors } \\
N=160\end{array}$ & $\begin{array}{l}\text { In-hospital death } \\
N=40\end{array}$ & $p$ \\
\hline Time since kidney transplantation (months) & $40[5-119]$ & $37[4-118]$ & 54 [12-122] & 0.14 \\
\hline \multicolumn{5}{|l|}{ Causes of admission (n, \%) } \\
\hline Acute respiratory failure & $55(27.5)$ & $42(26.3)$ & $13(32.5)$ & 0.43 \\
\hline Septic shock & $53(26.5)$ & $42(26.3)$ & $11(27.5)$ & 0.84 \\
\hline Unplanned surgery & $46(23)$ & $40(25)$ & $6(15)$ & 0.21 \\
\hline Cardiogenic shock & $18(9)$ & $12(7.5)$ & $6(15)$ & 0.21 \\
\hline Acute neurological condition & $12(6)$ & $9(5.6)$ & $3(7.5)$ & 0.71 \\
\hline Acute kidney injury & $10(5)$ & $10(6.3)$ & $0(0)$ & 0.22 \\
\hline Others & $6(3)$ & $5(3.1)$ & $1(2.5)$ & 1.00 \\
\hline \multicolumn{5}{|l|}{ Sepsis at the admission (n, \%) } \\
\hline Overall & $114(57)$ & 89 (55.6) & $25(63)$ & 0.48 \\
\hline Lung & $57(50)$ & $47(52.9)$ & $10(40)$ & 0.70 \\
\hline Urinary & $26(22.8)$ & $23(25.8)$ & $3(7.5)$ & 0.30 \\
\hline Peritonitis & $24(21)$ & $14(15.7)$ & $10(25)$ & 0.01 \\
\hline Others & $7(6.1)$ & $5(5.1)$ & $2(1.4)$ & 0.64 \\
\hline \multicolumn{5}{|l|}{ Organ failures (n, \%) } \\
\hline SOFA score & $6[4-8]$ & $6[4-8]$ & 8 [7-10] & $<0.001$ \\
\hline SAPS2 score & 50 [39-63] & 48 [37-59] & $67[57-77]$ & $<0.001$ \\
\hline \multicolumn{5}{|l|}{ Acute kidney injury (KDIGO) } \\
\hline stage 1 & $49(24.5)$ & $42(26.3)$ & $7(17.5)$ & \\
\hline stage 2 & $8(4)$ & $6(3.8)$ & $2(5)$ & \\
\hline stage 3 & $113(56.5)$ & $86(53.8)$ & $27(67.5)$ & 0.008 \\
\hline Renal replacement therapy & $103(51.5)$ & $76(47.5)$ & $27(67.5)$ & 0.03 \\
\hline Mechanical ventilation & $107(53.5)$ & $78(48.8)$ & $29(72.5)$ & 0.008 \\
\hline Vasopressive drugs & $97(48.5)$ & $68(42.5)$ & $29(72.5)$ & 0.001 \\
\hline Normalized prothrombin time $<50 \%$ & $11(5.5)$ & $5(3.1)$ & $6(15)$ & 0.01 \\
\hline RBC transfusion & $142(71)$ & $109(68.1)$ & $33(82.5)$ & 0.08 \\
\hline \multicolumn{5}{|l|}{ Immunosuppressive regimen (n, \%) } \\
\hline No change & $45(22.5)$ & $45(28.1)$ & $0(0)$ & 0.02 \\
\hline Increased dose of steroids & $136(68)$ & $100(62.5)$ & $36(90)$ & 0.2 \\
\hline Withdrawal of CNI & $40(20)$ & $25(15.6)$ & $15(37.5)$ & 0.004 \\
\hline Withdrawal of antimetabolites & $61(30)$ & $48(30)$ & $13(32.5)$ & 0.85 \\
\hline
\end{tabular}

\section{Predictive factors of in-hospital mortality}

Of the 200 patients, 25 (12.5\%), 40 (20\%) and 45 (22.5\%) died in the ICU, the hospital, or before day-90, respectively. After a median follow-up of 19 months [IQR 3-45], median survival was not reached and survival at month 80 was estimated at $60 \%$ (Fig. 2). Main causes of death in the ICU were sepsis in 16 patients, cardiogenic shock in 4 , cerebrovascular stroke in 2 , cancers in 2 , and fulminant hepatitis in 1.

By univariate analysis, predictive factors of in-hospital death were the following (Tables 1 and 2): history of peripheral arterial disease, immunosuppressive regimen without antimetabolites at admission, high gravity scores at day 1, organ failure (mechanical ventilation; vasopressive drugs; RRT; normalized prothrombin time $<50 \%$ at admission), and withdrawal of CNI in the ICU. In patients with available data, a history of positive EBV viremia or BK viruria was also predictive of death in hospital.

By multivariate analysis, SAPS2 score (OR 1.06, $\mathrm{IC}_{95 \%}$ [1.03-1.08], $p<0.0001)$ and CNI withdrawal in ICU (OR $\left.2.65, \mathrm{IC}_{95 \%}[1.11-6.32], p=0.027\right)$ were the only predictive factors of death during the hospital stay. When the analysis was conducted in the sub-group of patients with 


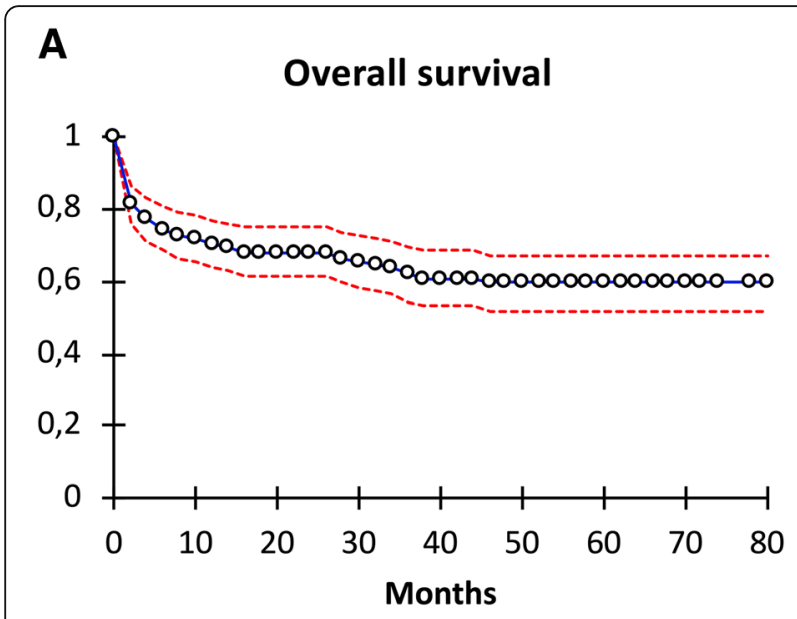

B

B Epstein Barr Virus DNAemia

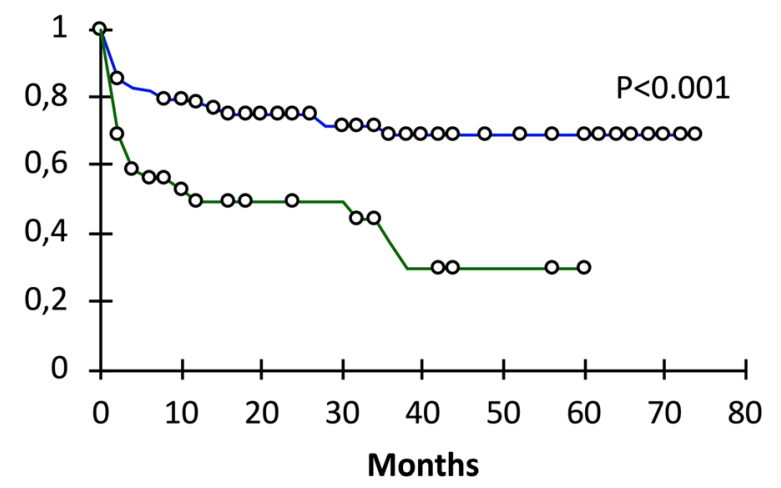

- No - Yes

Fig. 2 Survival curves following admission to the ICU. a. Overall population. b. Survival according to EBV replication before admission

available virology data $(n=127)$, the two factors that independently predicted the risk of death in hospital were the gravity SAPS2 score at admission (OR 1.07, $\mathrm{IC}_{95 \%}$ [1.03-1.11], $p=0.001)$ and a positive EBV viremia in the 6 months preceding the admission (OR 4.35, $\mathrm{IC}_{95 \%}$ [1.52-12.5], $p=0.006)$.

\section{Renal graft outcome}

As a secondary objective, we characterized the risk to develop AKI to CKD transition. Graft survival is shown in Fig. 3a. Median graft survival was 10 months. To better characterize the renal outcome and progression from AKI toward CKD in KTR admitted to the ICU, we studied the sub-group of patients with stable renal function at admission (i.e. admitted more than 1 month after the renal transplantation) and still alive 6 months after the admission to the ICU. In these 113 patients, median eGFR at month 6 was $35 \mathrm{~mL} / \mathrm{min} / 1.73 \mathrm{~m}^{2}$ [IQR 11-55], compared to $44 \mathrm{~mL} / \mathrm{min} / 1.73 \mathrm{~m}^{2}$ [IQR 27-61] before hospitalization in the ICU $(p=0.002)$. A progression of at least one stage in the CKD KDIGO classification was observed in $34(30.1 \%)$ and $51(45.1 \%)$ patients at 1 and 6 months, respectively (Fig. 3b). Staging of the CKD before the admission (stage $4-5,58 \%$ vs. stage $1-328.1 \%$, $p=0.006$ ) and the severity of AKI (stage $355.4 \%$ vs. stage $0-234.2 \%, p=0.04$ ) were significantly associated with a progression of the CKD stage at month 6 .

\section{Immunological outcomes}

Among the 119 patients with anti-HLA immunological status available before and 6 months after the admission to the ICU, 18 (15.1\%) developed anti-HLA antibodies after the ICU stay, including 11 with donor-specific antibodies (DSA; 9.2\%). Among these 18 patients, 6 had no detectable anti-HLA antibodies before admission, 7 had anti-HLA antibodies, and 5 had DSA. Two patients had an active ABMR, and two others stopped immunosuppressive drugs before admission. During the stay in ICU, 13 patients received RBC transfusions, and 4 needed transplant removal (urinoma, renal vein thrombosis, graft intolerance syndrome or emphysematous pyelonephritis). Two additional patients benefitted from transplant removal in the next 6 months. Patients that did not acquire HLA immunization during ICU had a significantly poorer renal prognosis (62 vs. $90 \%$ functional graft at 12 months; $p=0.06$ ).

\section{Discussion}

In this study, we reported the predictive factors of inhospital mortality in a large cohort of 200 KTR admitted to the ICU. Risk of transition from AKI to CKD, and anti-HLA immunization, were also reported. Notwithstanding the monocentric status of this study and the inherent biases of ICU admission and management, our ICU is the referral center for KTR requiring admission to the ICU (except for neurological and cardiac surgery) in a large region in the south-west of France ( $\sim 2.3$ million inhabitants). Thus, the studied cohort accurately described the causes of KTR admission to the ICU, characteristics at presentation, and specific outcomes.

Over the study period, the estimated incidence of ICU admission (7.7\%) was closed to the one reported in recent studies $(4.5$ to $10.2 \%)[2-5,7]$. Median time from renal transplantation to ICU admission was longer (41 months vs. 4.4 to 25.2 months $[1-5,7-9,18]$ ) except in one study [19]. The mortality rate was not influenced by the timing of ICU admission, thus confirming survival in the ICU is not associated to the characteristics of the transplantation $[2,5,20,21]$.

Our series confirms that ARF and sepsis are the main causes of ICU admission in KTR [1, 3-6, 9, 18, 20, 21]. 


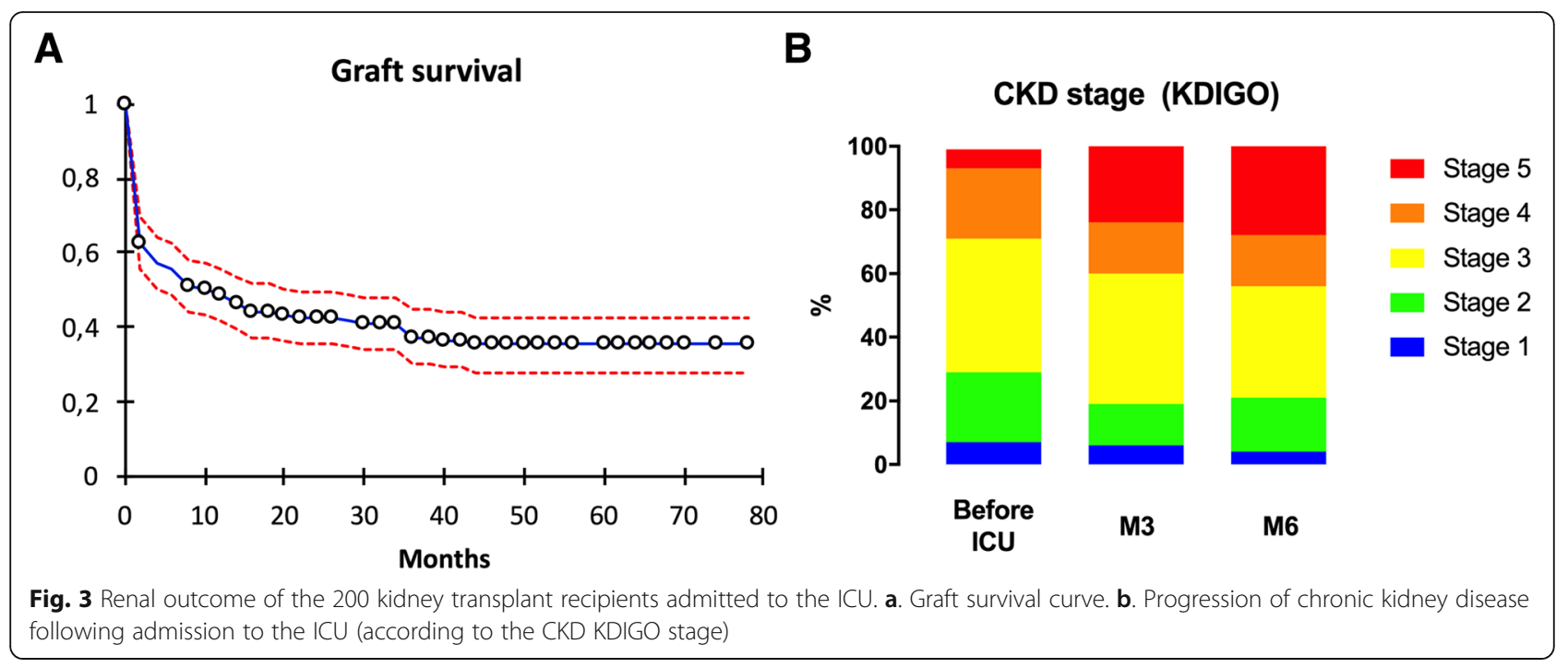

Lung infection was the main cause of ARF with acute pulmonary edema ranking second, pointing to the high risk of sodium overload in KTR (steroids, underlying CKD or heart disease). Multiple causes of ARF were identified in $11 \%$ of patients, confirming that management of KTR should follow a dedicated workup (transplantation history, immunosuppressive regimens, underlying chronic disorders) $[10,22]$. Here, $14.5 \%$ of the individuals admitted to the ICU for infection had at least two concomitant infections.

Contrasting to older studies $[5,6,21]$, the mortality rate in our study (i.e., $20 \%$ in the hospital and 26.5\% 6 months after the ICU stay) was lower than in unselected critically ill patients [23]. Of note, severity scores at the admission predicted mortality in hospital between 15 and $50 \%[24,25]$. This mortality rate, close to the one observed in two recent French studies, suggests that usual gravity scores may be undermined in KTR. Management of KTR in ICUs specialized in the field of transplantation and immunocompromised patients may also improves the outcome of these patients [3, 4]. Prognosis of solid organ transplant recipients with sepsis may be better than expected in unselected critically ill patients after adjustments on gravity scores, causes of admission, and number of organ failures [26]. Immunosuppressive drugs with reduction of the risk of hyper-inflammation state and subsequent refractory acute respiratory distress syndrome or shock may account for this discrepancy.

Interestingly, we showed for the first time that EBV replication in the months preceding the admission of KTR to the ICU was associated with a poorer outcome. EBV replication per se is not associated with a poorer outcome in unselected KTR [27]. However, chronic EBV replication may be the trigger or the consequence of $\mathrm{T}$ cell exhaustion, an acquired immune paralysis observed in patients with chronic exposure to viral or cancer antigens [28], associated with an increased risk of mortality or nosocomial infections in patient admitted in ICU for sepsis, burns or traumas [29]. Chronic EBV replication may thus be a surrogate marker of frailty associated with a higher risk of mortality in ICU. Further studies are warranted to confirm that EBV status at the time of admission in ICU may help to identify patients at high risk of death.

In our cohort, AKI was highly prevalent (81.5\%) and $51.5 \%$ of patients required RRT, contrasting with unselected critically ill patients (19 to $57 \%$ and 4.5 to $13.5 \%$, respectively) [30, 31]. In addition to known risk factors for the development of AKI in the ICU, the use of calcineurin inhibitors, the previous episodes of AKI and the underlying CKD, all increased the risk of AKI in KTR with acute condition [13, 14, 32, 33]. Moreover, we showed that progression of CKD after admission to the ICU is highly prevalent (30\% at 1 month and $45 \%$ at 6 months in our series, compared to $12-20 \%$ at 3 months in older studies $[3,4,11]$ and was well predicted by the basal CKD stage and the severity of the AKI. The high incidence of transition toward CKD in KTR, which continues beyond month 3 , also points to additional and persistent renal injuries specifically encountered in this population. Whether specific management in ICU regarding the immunosuppressive regimen [10], prophylaxis of cytomegalovirus proliferation [34], and RBC transfusion policies [15] may help to overcome the risk to develop anti-HLA antibodies after admission to the ICU (15.1\% of survivors in our series) in solid organ transplantation recipients need to be tested in prospective trials, because our retrospective study cannot lead to specific recommendations.

Several limitations may be underlined. First, the retrospective design of the study prevented the assessment of EBV viremia in all the KTR admitted to the ICU during 
the inclusion period. Nonetheless, this parameter was available in a significant number of patients $(n=127)$. Second, management of immunosuppressive regimen may vary during the ICU stay according to the patient status. Here, we discriminate patients according the maintain or the withdrawal of immunosuppressive drugs but how long patients had reduced immunosuppressive regimen was unknown in most patients. This limitation may also have modulated the risk of HLA immunization. Last, we reported here a large cohort of KTR admitted to the ICU in order to describe the different clinical scenarios that can lead to ICU admission in these patients. However, the various causes of admission introduced heterogeneity in term of both mortality and risk of immunization that need to be taken in account. It also prevents to draw firm conclusions about the optimal immunosuppressive management.

In summary, we showed that survival of KTR following admission to the ICU is predicted by the severity of the acute condition but also by viral replication (i.e., the underlying immune defense status). ICU admission is associated with a very high risk of AKI and progression toward CKD, as well as a significant risk of HLA immunization.

\section{Abbreviations \\ ABMR: Antibodies-Mediated Rejection; AKI: Acute Kidney Injury; CKD: Chronic Kidney Disease; CMV: Cytomegalovirus; CNI : Calcineurin Inhibitors; DSA: Donor-Specific Antibodies; EBV: Epstein Barr Virus; GFR: Glomerular Filtration Rate; HLA: Human Leukocytes Antigens; ICU: Intensive Care Unit; KTR: Kidney Transplant Recipients; RBC: Red Blood Cells; RRT: Renal Replacement Therapy; TCMR: T-Cells Mediated Rejection}

\section{Acknowledgments}

None

\section{Authors' contributions}

SF and DG designed the study; SF, DG and NKD analyzed the patient data; SF, NK and DG wrote the manuscript; SF, LL, MBN, OC, NK, ADB, DG, ALH, OR and LE followed patients; NC preformed immunological analyses. All authors read and approved the final manuscript.

\section{Funding}

None

\section{Availability of data and materials}

The datasets used and/or analyzed during the current study are available from the corresponding author on reasonable request.

\section{Ethics approval and consent to participate}

This retrospective observational study was conducted according to our Institutional Review Board instructions (University Hospital of Toulouse Office of Research, Development and Innovation).

\section{Consent for publication}

Not applicable

\section{Competing interests}

The authors declare that they have no competing interests.

\section{Author details}

'Département de Néphrologie et Transplantation d'organes, Unité de Réanimation, Hôpital Rangueil, Centre Hospitalier Universitaire de Toulouse, 1, avenue Jean Poulhes, 31059 Toulouse, France. ${ }^{2}$ Laboratoire
d'Immunologie, Hôpital Rangueil, Centre Hospitalier Universitaire de Toulouse, F-31000 Toulouse, France. ${ }^{3}$ Université Paul Sabatier, Toulouse III, F-31000 Toulouse, France. ${ }^{4}$ Institut National de la Santé et de la Recherche Médicale, U1043, IFR-BMT, CHU Purpan, Toulouse, France. Institut National de la Santé et de la Recherche Médicale, Institut des Maladies Métaboliques et Cardiovasculaires, U1048 (Renal Fibrosis lab), and French Intensive care Renal Network (F.I.R.N), Toulouse, France.

Received: 25 January 2019 Accepted: 5 July 2019

Published online: 17 July 2019

\section{References}

1. Kirilov D, Cohen J, Shapiro M, Grozovski E, Singer P. The course and outcome of renal transplant recipients admitted to a general intensive care unit. Transplant Proc. 2003;35:606 http://www.ncbi.nlm.nih.gov/ pubmed/12644065. Accessed 26 Jan 2018.

2. Klouche $K$, Amigues L, Massanet P, Garrigue V, Delmas S, Szwarc I, et al. Outcome of renal transplant recipients admitted to an intensive care unit: a 10-year cohort study. Transplantation. 2009;87:889-95. https://doi. org/10.1097/TP.0b013e31819a688a.

3. Bige N, Zafrani L, Lambert J, Peraldi M-N, Snanoudj R, Reuter D, et al. Severe infections requiring intensive care unit admission in kidney transplant recipients: impact on graft outcome. Transpl Infect Dis. 2014;16:588-96. https://doi.org/10.1111/tid.12249.

4. Canet E, Osman D, Lambert J, Guitton C, Heng A-E, Argaud L, et al. Acute respiratory failure in kidney transplant recipients: a multicenter study. Crit Care. 2011;15:R91. https://doi.org/10.1186/cc10091.

5. Mouloudi E, Massa E, Georgiadou E, losifidis E, Kydona C, Sgourou K, et al. Course and outcome of renal transplant recipients admitted to the intensive care unit: a 20-year study. Transplant Proc. 2012;44:271820. https://doi.org/10.1016/j.transproceed.2012.09.097.

6. Arulkumaran N, West S, Chan K, Templeton M, Taube D, Brett SJ. Longterm renal function and survival of renal transplant recipients admitted to the intensive care unit. Clin Transpl. 2012;26:E24-31. https://doi.org/1 0.1111/j.1399-0012.2011.01520.x.

7. Ulas A, Kaplan S, Zeyneloglu P, Torgay A, Pirat A, Haberal M. Acute respiratory failure in renal transplant recipients: a single intensive care unit experience. Exp Clin Transplant. 2015;13(Suppl 3):44-7. https://doi.org/10.6 002/ect.tdtd2015.037.

8. Shorr AF, Abbott KC, Agadoa LY. Acute respiratory distress syndrome after kidney transplantation: epidemiology, risk factors, and outcomes. Crit Care Med. 2003;31:1325-30. https://doi.org/10.1097/01.CCM. 0000053645.38356.A6.

9. de Carvalho MA, Freitas FGR, Silva Junior HT, Bafi AT, Machado FR, Pestana JOM. Mortality predictors in renal transplant recipients with severe Sepsis and septic shock. PLoS One. 2014;9:e111610. https://doi. org/10.1371/journal.pone.0111610.

10. Canet E, Zafrani L, Azoulay É. The critically ill kidney transplant recipient: a narrative review. Chest. 2016;149:1546-55. https://doi.org/10.1016/j.chest.2 016.01.002.

11. Badin J, Longuet H, Guillon A, Barbet C, Halimi JM, Lebranchu Y, et al. Renal function of renal transplantation patients after hospitalization in an intensive care unit. Transplant Proc. 2012;44:2792-4. https://doi.org/10.1016/ j.transproceed.2012.09.027.

12. Hsu RK, Hsu C-Y. The role of acute kidney injury in chronic kidney disease. Semin Nephrol. 2016;36:283-92. https://doi.org/10.1016/j. semnephrol.2016.05.005

13. Mehrotra A, Rose C, Pannu N, Gill J, Tonelli M, Gill JS. Incidence and consequences of acute kidney injury in kidney transplant recipients. Am J Kidney Dis. 2012;59:558-65. https://doi.org/10.1053/j.ajkd.2011.11.034.

14. Filiponi TC, Requião-Moura LR, Tonato EJ, Carvalho de Matos AC, e SilvaFilho AP, de Souza Durão Junior M. Hospital admission following acute kidney injury in kidney transplant recipients is associated with a negative impact on graft function after 1-year. PLoS One. 2015;10:e0138944. https:// doi.org/10.1371/journal.pone.0138944.

15. Ferrandiz I, Congy-Jolivet N, Del Bello A, Debiol B, Trébern-Launay K, Esposito L, et al. Impact of early blood transfusion after kidney transplantation on the incidence of donor-specific anti-HLA antibodies. Am J Transplant. 2016;16:2661-9. https://doi.org/10.1111/ ajt.13795. 
16. Kamar N, Del Bello A, Belliere J, Rostaing L. Calcineurin inhibitor-sparing regimens based on mycophenolic acid after kidney transplantation. Transpl Int. 2015;28:928-37. https://doi.org/10.1111/tri.12515.

17. Kellum JA, Lameire N, KDIGO AKI. Guideline work group. Diagnosis, evaluation, and management of acute kidney injury: a KDIGO summary (part 1). Crit Care. 2013;17:204. https://doi.org/10.1186/ cC11454.

18. Marques IDB, Caires RA, Machado DJB, Goldenstein PT, Rodrigues CE, Pegas JCR, et al. Outcomes and mortality in renal transplant recipients admitted to the intensive care unit. Transplant Proc. 2015;47:2694-9. https://doi.org/10.1016/j.transproceed.2015.07.035.

19. Tu G, Ju M, Zheng Y, Zhu D, Xu M, Rong R, et al. An interdisciplinary approach for renal transplant recipients with severe pneumonia: a single ICU experience. Intensive Care Med. 2014;40:914-5. https://doi.org/10.1007/ s00134-014-3296-6.

20. Sadaghdar H, Chelluri L, Bowles SA, Shapiro R. Outcome of renal transplant recipients in the ICU. Chest. 1995;107:1402-5 http://www.ncbi.nlm.nih.gov/ pubmed/7750338. Accessed 26 Jan 2018.

21. Aldawood A. The course and outcome of renal transplant recipients admitted to the intensive care unit at a tertiary hospital in Saudi Arabia. Saudi J Kidney Dis Transpl. 2007;18:536-40 http://www.ncbi.nlm.nih.gov/ pubmed/17951939. Accessed 26 Jan 2018.

22. Schnell D, Mayaux J, Lambert J, Roux A, Moreau A-S, Zafrani L, et al. Clinical assessment for identifying causes of acute respiratory failure in cancer patients. Eur Respir J. 2013;42:435-43. https://doi.org/10.1183/09031936. 00122512.

23. Allyn J, Ferdynus C, Bohrer M, Dalban C, Valance D, Allou N. Simplified acute physiology score II as predictor of mortality in intensive care units: a decision curve analysis. PLoS One. 2016;11:e0164828. https://doi.org/10.13 71/journal.pone.0164828.

24. Vincent JL, Moreno R, Takala J, Willatts S, De Mendonça A, Bruining H, et al. The SOFA (Sepsis-related organ failure assessment) score to describe organ dysfunction/failure. On behalf of the working group on Sepsis-related problems of the European Society of Intensive Care Medicine. Intensive Care Med. 1996;22:707-10 http://www.ncbi.n/m.nih.gov/pubmed/8844239. Accessed 26 Jan 2018.

25. Vincent $J$, de Mendonça A, Cantraine F, Moreno R, Takala J, Suter PM, et al. Use of the SOFA score to assess the incidence of organ dysfunction/failure in intensive care units: results of a multicenter, prospective study. Working group on \&quot;sepsis-related problems\&quot; of the European Society of Intensive Care Medicine. Crit Care Med. 1998;26:1793-800 http://www.ncbi.nlm.nih.gov/pubmed/ 9824069. Accessed 26 Jan 2018.

26. Kalil AC, Syed A, Rupp ME, Chambers H, Vargas L, Maskin A, et al. Is Bacteremic Sepsis associated with higher mortality in transplant recipients than in nontransplant patients? A matched case-control propensity-adjusted study. Clin Infect Dis. 2015;60:216-22. https://doi. org/10.1093/cid/ciu789.

27. Morton M, Coupes B, Roberts SA, Johnson SL, Klapper PE, Vallely PJ, et al. Epstein-Barr virus infection in adult renal transplant recipients. Am J Transplant. 2014;14:1619-29. https://doi.org/10.1111/ajt.12703.

28. Schietinger A, Greenberg PD. Tolerance and exhaustion: defining mechanisms of T cell dysfunction. Trends Immunol. 2014;35:51-60. https:// doi.org/10.1016/j.it.2013.10.001.

29. van Vught LA, Klein Klouwenberg PMC, Spitoni C, Scicluna BP, Wiewel MA, Horn J, et al. Incidence, risk factors, and attributable mortality of secondary infections in the intensive care unit after admission for Sepsis. JAMA. 2016 315:1469. https://doi.org/10.1001/jama.2016.2691.

30. Hoste EAJ, Bagshaw SM, Bellomo R, Cely CM, Colman R, Cruz DN, et al. Epidemiology of acute kidney injury in critically ill patients: the multinational AKI-EPI study. Intensive Care Med. 2015;41:1411-23. https:// doi.org/10.1007/s00134-015-3934-7.

31. Bouchard J, Acharya A, Cerda J, Maccariello ER, Madarasu RC, Tolwani AJ, et al. A prospective international multicenter study of AKI in the intensive care unit. Clin J Am Soc Nephrol. 2015;10:1324-31. https://doi.org/10.2215/CJN. 04360514.

32. Nagarajan $M$, Ramanathan $S$, Dhanapriya J, Dineshkumar $T$, Subramaniyan TB, Gopalakrishnan N. Impact of acute kidney injury on renal allograft survival. Ren Fail. 2017;39:40-4. https://doi.org/10.1080/ 0886022X.2016.1244076
33. Nakamura M, Seki G, Iwadoh K, Nakajima I, Fuchinoue S, Fujita T, et al. Acute kidney injury as defined by the RIFLE criteria is a risk factor for kidney transplant graft failure. Clin Transpl. 2012;26:520-8. https://doi.org/10.1111/ j.1399-0012.2011.01546.x

34. Pouteil-Noble C, Ecochard R, Landrivon G, Donia-Maged A, Tardy JC, Bosshard S, et al. Cytomegalovirus infection--an etiological factor for rejection? A prospective study in 242 renal transplant patients. Transplantation. 1993;55:851-7 http://www.ncbi.nlm.nih.gov/pubmed/ 8386406. Accessed 26 Jan 2018.

\section{Publisher's Note}

Springer Nature remains neutral with regard to jurisdictional claims in published maps and institutional affiliations.
Ready to submit your research? Choose BMC and benefit from:

- fast, convenient online submission

- thorough peer review by experienced researchers in your field

- rapid publication on acceptance

- support for research data, including large and complex data types

- gold Open Access which fosters wider collaboration and increased citations

- maximum visibility for your research: over $100 \mathrm{M}$ website views per year

At BMC, research is always in progress.

Learn more biomedcentral.com/submissions 